\title{
Komitmen Organisasi Karyawan dan Pengaruhnya terhadap Organizational Citizenship Behavior (OCB)
}

\author{
Elita Halimsetiono ${ }^{1 *}$, Winnie Nirmala Santosa ${ }^{1}$ \\ ${ }^{1}$ Fakultas Kedokteran, Universitas Surabaya, Surabaya-Indonesia \\ * corresponding author: elitahalims@staff.ubaya.ac.id
}

Abstract-Commitment is an important and fundamental form in which the concept is widely used in the assessment of individual attitudes in various environments, including universities. In several previous studies, it had been found that there was a relationship between organizational commitment and $O C B$, where the higher the organizational commitment, the higher the OCB. This analytic observational study used a cross-sectional design to analyze the effect of organizational commitment on employees' OCB at Surabaya University. A total sample of 190 permanent employees (non-lecturers) was collected from 27 work units at Surabaya University. Quota sampling was used for sample selection. Collecting data using a questionnaire containing the scale of organizational commitment and OCB. This study indicated that majority of employees had moderate organizational commitment and OCB. Simultaneously, multiple linear regression analysis showed that both organizational commitment and demographic characteristics had a significant effect on OCB. Partially, normative commitment and education level had a significant and positive influence on OCB. Employees' OCB was more influenced by normative commitment than by education level. The results of this study are important as an input for the organization to pay more attention to these two aspects in improving its employees' OCB.

Keywords: employees, organizational citizenship behavior, organizational commitment

\begin{abstract}
Abstrak-Komitmen merupakan bentuk yang penting dan mendasar yang mana konsep tersebut banyak digunakan dalam penilaian sikap individu di berbagai lingkungan, termasuk juga lingkungan perguruan tinggi. Dalam beberapa penelitian terdahulu, telah ditemukan adanya hubungan antara komitmen organisasi dan OCB, dimana semakin tinggi komitmen organisasi, maka akan semakin tinggi pula OCB yang dimiliki. Penelitian yang bersifat analitik observasional dengan rancang bangun cross-sectional ini bertujuan menganalisis pengaruh komitmen organisasi terhadap OCB karyawan di Universitas Surabaya. Sejumlah 190 orang karyawan tetap (non dosen) dari 27 unit kerja di Universitas Surabaya menjadi sampel penelitian ini. Metode pemilihan sampel yang digunakan adalah quota sampling. Pengumpulan data menggunakan kuesioner yang berisikan skala komitmen organisasi dan OCB. Mayoritas karyawan memiliki komitmen organisasi dan OCB tingkat sedang. Secara simultan, analisis regresi linier berganda menunjukkan baik komitmen organisasi maupun karakteristik demografi memiliki pengaruh yang bermakna terhadap OCB. Secara parsial, komitmen normatif maupun tingkat pendidikan memiliki pengaruh yang bermakna dan positif terhadap OCB. OCB karyawan lebih dipengaruhi oleh komitmen normatif daripada tingkat pendidikan. Hasil penelitian ini penting sebagai bahan masukan bagi organisasi agar lebih memperhatikan kedua aspek tersebut dalam meningkatkan OCB karyawannya.
\end{abstract}

Kata kunci: karyawan, komitmen organisasi, organizational citizenship behavior

\section{PENDAHULUAN}

Ramli (2008) mengemukakan agar sumber daya manusia di Indonesia mempunyai kemampuan untuk bersaing di era global, maka diperlukan tanggung jawab besar untuk menciptakan sumber daya manusia tangguh mulai dari usia pra sekolah hingga strata tiga (doktoral) pada perguruan tinggi. Dengan adanya tiga level strata pendidikan yang penting dalam perguruan tinggi, sehingga dinyatakan bahwa perguruan tinggi memiliki peran serta yang sangat besar pada proses pembentukan sumber daya manusia tersebut.

Perguruan tinggi dalam kapasitasnya sebagai suatu lembaga pendidikan yang bertujuan jelas dan tegas dalam lingkup akademik maupun profesional serta mampu berkarya pada tingkat lokal, regional, nasional hingga internasional memiliki konsekuensi logis untuk menjawab era perdagangan bebas di masa mendatang agar mampu bersaing dan mengembangkan pasarnya. Sehubungan dengan hal itu, maka perguruan tinggi perlu memperhatikan aspek-aspek penting yang dapat menciptakan suatu sistem internal yang solid dan cara yang dapat memberikan rasa puas pada pelanggannya (mahasiswa), sehingga memberikan potensi bagi pengembangan organisasi secara keseluruhan (Djati \& Rini, 2011). Perguruan tinggi perlu mengetahui cara untuk meningkatkan pelayanan yang prima pada pelanggan (mahasiswa) nya dan faktor apa yang berperan pada kualitas pelayanan tersebut (Olorunniwo, Hsu, \& Udo, 2006).

Adapun faktor yang dapat berperan pada kualitas pelayanan tersebut diantaranya adalah komitmen organisasi dan OCB karyawan. Sehubungan dengan hal tersebut, penelitian 
ini secara umum bertujuan untuk menganalisis pengaruh komitmen organisasi terhadap OCB karyawan di Universitas Surabaya, dan secara khusus bertujuan untuk mengidentifikasi karakteristik demografi, komitmen organisasi, dan OCB karyawan di Universitas Surabaya.

Kinerja dinyatakan sebagai hasil kerja sesuai dengan tanggung jawab dan wewenang yang dimiliki individu ataupun kelompok dalam sebuah organisasi, demi tercapainya tujuan organisasi secara sah dan sesuai dengan aturan hukum, moral maupun etika (Syauta, Eka, Margono, \& Solimun, 2012). Karyawan yang berperilaku positif, bermoral baik, selalu mendukung organisasi, patuh terhadap segala peraturan dan berbagai prosedur dalam organisasi akan membawa keuntungan bagi organisasi. Bentuk perilaku individual yang dapat meningkatkan efektivitas organisasi dikenal sebagai organizational citizenship behavior (OCB) (Rahmawati \& Prasetya, 2017).

Dalam hubungannya dengan perilaku karyawan diatas, maka hal penting yang perlu diperhatikan dalam membangun OCB di lingkungan kerja adalah komitmen yang terdapat dalam diri setiap karyawan. Menurut Sena (2011), ada beberapa hal yang mendorong timbulnya OCB karyawan, dimana diantaranya dipengaruhi oleh komitmen pada organisasi berupa adanya keinginan untuk dapat berperan serta dalam organisasi dengan baik, dan adanya perasaan bangga dirinya merupakan bagian dari organisasi. Individu yang memiliki komitmen pada organisasinya adalah individu yang mampu mengidentifikasikan dirinya dengan organisasi, mau berpartisipasi dan terlibat dalam organisasi, serta menunjukkan kesetiaan kepada organisasi (Javanmard, Mo'tamedi, \& Pirmorad, 2014). Demikian pula dengan Salajagheh, Safdaryan dan Kheyri (2014) yang mengungkapkan bahwa komitmen merupakan bentuk yang penting dan mendasar, sehingga konsep tersebut sejak dulu banyak digunakan dalam penilaian sikap individu di berbagai lingkungan, termasuk dalam lingkungan perguruan tinggi.

Dari penjelasan tersebut dapat diketahui adanya pengaruh komitmen organisasi terhadap OCB karyawan, sehingga hipotesis dalam penelitian ini adalah ada pengaruh komitmen organisasi terhadap OCB karyawan di Universitas Surabaya.

\section{METODE}

Penelitian yang dilakukan pada Januari - Juni 2018 ini bersifat analitik observasional dan memiliki rancang bangun cross-sectional. Seluruh karyawan tetap (non-dosen) yang terdapat di Universitas Surabaya pada tahun 2017 yang berjumlah 358 orang menjadi populasi pada penelitian ini. Besar sampel total yang memenuhi persyaratan adalah 190 orang karyawan dan berasal dari 27 unit kerja di Universitas Surabaya, dan ditentukan melalui rumus Krejcie dan Morgan "Educational and Psychological Measurement" (Supriyanto dan Djohan, 2011):

$$
S=\frac{X^{2} \cdot N \cdot p(1-p)}{d^{2}(N-1)+X^{2} \cdot p(1-p)}
$$

Keterangan:

$\mathrm{S}=$ besar sampel yang diinginkan

$\mathrm{N}=$ besar populasi

$\mathrm{p}=$ taksiran proporsi $(0,50)$

$\mathrm{d}=$ degree of realiability $(0,05)$

$X^{2}=$ nilai table Chi-Square untuk 1 degree of freedom, confidence level 0,95 $=3,841$

Metode pengambilan sampel adalah proporsional sampling, yakni pada tiap unit kerja diambil 50\% dari keseluruhan karyawan yang ada, sehingga diperoleh sampel sejumlah 190 orang (memenuhi jumlah sampel dari perhitungan rumus Krejcie dan Morgan)

Pengumpulan data penelitian menggunakan kuesioner yang berisi Skala Komitmen Organisasi dan Skala Organizational Citizenship Behavior (OCB). Variabel komitmen organisasi dinilai dengan menggunakan 24 item skala dari Meyer dan Allen (Jaros, 2007) yang terdiri atas tiga aspek komitmen yaitu afektif, kontinuans, dan normative, yang tiap aspeknya terdiri atas 
delapan item. Skala likert 4 poin yang berkisar dari nilai 1 (sangat tidak setuju) sampai nilai 4 (sangat setuju) digunakan responden untuk menunjukkan tingkat kesepakatan mereka pada setiap pernyataan dalam skala ini. Contohnya: saya merasa merupakan bagian keluarga dari organisasi ini. Sedangkan variabel OCB dinilai dengan menggunakan 15 item skala dari Podsakoff (Kumar \& Shah, 2015). Aspek dari OCB, yaitu altruisme, courtesy, civic virtue, sportsmanship, dan conscientiousness masing-masing terdiri dari 3 item. Skala likert 4 poin yang berkisar dari nilai 1 (tidak pernah) sampai nilai 4 (sangat sering) digunakan responden untuk menunjukkan tingkat keseringan mereka dalam melakukan perilaku pada setiap pernyataan dalam skala ini. Contohnya: saya rela membantu sesama teman kerja saat mereka memiliki masalah yang terkait dengan pekerjaan.

Hasil uji validitas dan reliabilitas instrumen membuktikan bahwa alat ukur dalam penelitian ini valid dan reliabel.

Tabel 1

Hasil Uji Validitas Instrumen

\begin{tabular}{lcc}
\hline Variabel & R hitung (min. - max.) & Keterangan \\
\hline Komitmen Organisasi & $0,167-0,728$ & Valid \\
Organizational Citizenship Behavior & $0,524-0,708$ & Valid \\
\hline Keterangan: Valid jika nilai R hitung $>$ R tabel $(0,1424)$ & &
\end{tabular}

Tabel 2

Hasil Uji Reliabilitas Instrumen

\begin{tabular}{lcc}
\hline \multicolumn{1}{c}{ Variabel } & Cronbach's Alpha & Keterangan \\
\hline Komitmen Organisasi & 0,908 & Reliabel \\
Organizational Citizenship Behavior & 0,885 & Reliabel \\
\hline
\end{tabular}

Keterangan: Reliabel jika nilai Cronbach's Alpha >0,60

Analisis data dilakukan secara deskriptif untuk mengetahui deskripsi dari tiap variabel yang diteliti, dan secara analitik untuk mengetahui pengaruh secara bersamaan dari variabel bebas terhadap variabel terikatnya. Teknik analisis yang digunakan adalah analisis regresi linier berganda, dan sebelumnya telah dilakukan uji asumsi klasik untuk menilai normalitas, multikolinearitas, dan heteroskedastisitas data.

HASIL

Sebagian besar karyawan dalam penelitian ini berusia $>40$ tahun $(64,7 \%)$, berjenis kelamin laki-laki $(58,9 \%)$, memiliki tingkat pendidikan S1 $(43,2 \%)$, telah menikah $(83,2 \%)$, dan masa kerjanya $\geq 15$ tahun (66,3\%). Mayoritas karyawan memiliki komitmen afektif tingkat sedang $(51,1 \%)$, komitmen kontinuans tingkat sedang $(72,6 \%)$, komitmen normatif tingkat sedang $(71,1 \%)$, dan OCB tingkat sedang $(57,9 \%)$. 


\section{Uji Asumsi Klasik}

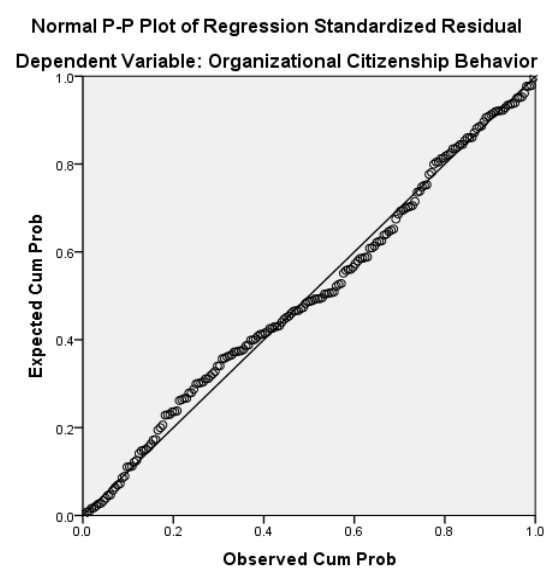

Gambar 1. Hasil uji normalitas data.

Uji normalitas data membuktikan adanya data yang tersebar di sekitar garis diagonal serta mengikuti arah garis diagonal, sehingga disimpulkan bahwa data berdistribusi normal. Normalitas data juga dibuktikan melalui Uji Kolmogorov Smirnov yang menunjukkan Asymp. Sig. (2-tailed) sebesar 0,200>0,05.

\section{Tabel 3}

Hasil Uji Multikolinearitas Data

\begin{tabular}{lcc}
\hline \multicolumn{1}{c}{ Variabel (Sub Variabel) } & Tolerance & VIF \\
\hline Umur & 0,174 & 5,742 \\
Jenis Kelamin & 0,704 & 1,421 \\
Tk Pendidikan & 0,663 & 1,508 \\
St Pernikahan & 0,770 & 1,299 \\
Masa Kerja & 0,187 & 5,338 \\
Komitmen Afektif & 0,505 & 1,979 \\
Komitmen Kontinuans & 0,587 & 1,703 \\
Komitmen Normatif & 0,633 & 1,579 \\
\hline
\end{tabular}

Uji multikolinearitas data membuktikan bahwa nilai Tolerance $>0,1$ dan nilai VIF (Variance Inflation Factor) < 10, sehingga disimpulkan tidak terdapat multikolinearitas data.

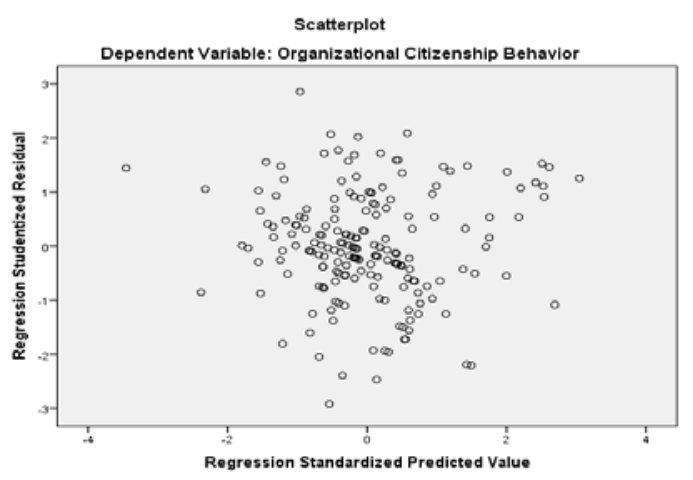

Gambar 2. Hasil uji heteroskedastisitas data.

Uji heteroskedastisitas data membuktikan tidak adanya pola yang jelas dari scatterplot, selain itu didapatkan titik-titik yang tersebar diatas maupun di bawah nilai 0 dari sumbu $\mathrm{Y}$, sehingga disimpulkan tidak ada heteroskedastisitas data. 


\section{Analisis Regresi Linier Berganda}

Hasil analisis regresi linier berganda dalam penelitian ini adalah sebagai berikut:

Tabel 4

Hasil Analisis Regresi Linier Berganda (Simultan)

\begin{tabular}{|c|c|c|c|c|c|c|}
\hline & Model & $\begin{array}{c}\text { Sum of } \\
\text { Squares }\end{array}$ & df & $\begin{array}{l}\text { Mean } \\
\text { Square }\end{array}$ & F hitung & $\mathbf{p}$ \\
\hline \multirow[t]{3}{*}{1} & Regression & 142,782 & 8 & 17,848 & 5,572 & 0,000 \\
\hline & Residual & 579,768 & 181 & 3,203 & & \\
\hline & Total & 722,550 & 189 & & & \\
\hline
\end{tabular}

Analisis regresi linier berganda membuktikan bahwa semua aspek komitmen organisasi (komitmen afektif, komitmen kontinuans, komitmen normatif) maupun semua aspek karakteristik demografi (umur, jenis kelamin, tingkat pendidikan, status pernikahan, masa kerja) secara simultan menunjukkan pengaruh yang bermakna terhadap OCB $(p=0,000)$.

Tabel 5

Hasil Analisis Regresi Linier Berganda (Parsial)

\begin{tabular}{lccc}
\hline \multicolumn{1}{c}{$\begin{array}{c}\text { Variabel } \\
\text { (Sub Variabel) }\end{array}$} & Beta & $\mathbf{p}$ & Deskripsi \\
\hline Umur & $-0,249$ & 0,121 & Tidak signifikan \\
Tingkat Pendidikan & 0,179 & 0,030 & Signifikan \\
Masa Kerja & 0,188 & 0,224 & Tidak signifikan \\
Komitmen Afektif & 0,116 & 0,217 & Tidak signifikan \\
Komitmen Kontinuans & 0,122 & 0,160 & Tidak signifikan \\
Komitmen Normatif & 0,261 & 0,002 & Signifikan \\
\hline Keterangan: $p<\alpha(0,05)=$ signifikan, analisis regresi linier berganda & &
\end{tabular}

Analisis regresi linier berganda membuktikan bahwa secara parsial komitmen normatif $(p=0,002 ; \beta=0,261)$ maupun tingkat pendidikan $(p=0,030 ; \beta=0,179)$ menunjukkan pengaruh yang positif dan bermakna terhadap $O C B$, selain itu dibuktikan pula bahwa dibandingkan tingkat pendidikan, komitmen normatif menunjukkan pengaruh yang lebih bermakna terhadap OCB.

\section{BAHASAN}

Tujuan dari penelitian ini adalah untuk menganalisis pengaruh komitmen organisasi terhadap organizational citizenship behavior (OCB) karyawan tetap (non dosen) di Universitas Surabaya. Hasil penelitian ini secara simultan membuktikan bahwa semua aspek komitmen organisasi menunjukkan pengaruh yang bermakna terhadap $O C B$, namun secara parsial hanya komitmen normatif yang menunjukkan pengaruh positif dan bermakna terhadap OCB, dalam arti jika seorang karyawan memiliki komitmen normatif yang tinggi, maka karyawan tersebut akan memiliki OCB yang tinggi pula. Hasil diatas serupa dengan hasil penelitian Kurniawan (2015) yang membuktikan bahwa secara simultan komitmen organisasi menunjukkan pengaruh yang bermakna terhadap $\mathrm{OCB}$, sedangkan komitmen normatif secara parsial menunjukkan pengaruh yang positif dan bermakna terhadap OCB. Demikian pula dengan penelitian Bolat dan Bolat (2008) pada bisnis perhotelan, dimana ditemukan hubungan yang bermakna diantara seluruh aspek komitmen organisasi dan $O C B$, namun komitmen normatif merupakan aspek komitmen organisasi yang memiliki hubungan terkuat dengan OCB. 
Menurut Wulandari (2015), komitmen organisasi dinyatakan sebagai usaha karyawan untuk terlibat dalam perusahaan dan tidak ingin meninggalkannya. Karyawan yang memiliki komitmen organisasi yang tinggi berkeinginan untuk tidak meninggalkan organisasi, bekerja sebaik mungkin, dan merasa turut memiliki organisasi, sehingga dirinya secara sukarela akan melakukan sesuatu yang membawa keuntungan bagi organisasi (conscientiousness). Karyawan dapat menerima dan patuh pada setiap peraturan dan kebijakan yang ada dalam organisasi apabila karyawan tersebut mempunyai kesamaan nilai dengan organisasi (sportsmanship). Demi kemajuan dan kelancaran organisasi, karyawan akan bekerja keras untuk meningkatkan kualitas kerjanya dan menghasilkan kinerja yang baik, serta akan berempati untuk menolong rekan sekerja yang beban kerjanya berlebih (altruism), sehingga hal itu akan menimbulkan kepedulian diantara karyawan dan menghindari timbulnya masalah dalam bekerja maupun dalam hubungan dengan atasan dan rekan sekerja (courtesy). Karyawan yang bertujuan sama dengan organisasi akan bekerja bukan hanya karena mengharapkan imbalan, namun dengan sukarela, ikhlas, dan penuh tanggung jawab demi kemajuan organisasi (civic virtue). Karyawan juga akan lebih menghargai waktu, mengutamakan kepentingan organisasi, mengikuti perubahan organisasi, dan patuh pada peraturan yang berlaku.

Meyer dan Allen dalam Suwandewi dan Sintaasih (2016) berpendapat bahwa timbulnya komitmen afektif disebabkan karena adanya hubungan emosional karyawan terhadap organisasinya, sehingga karyawan tidak ingin meninggalkan pekerjaannya karena mereka menginginkannya (Greenberg \& Baron, 2008). Adapun komitmen kontinuans timbul karena karyawan sadar akan kerugian yang dialami jika keluar dari organisasi (Suwandewi \& Sintaasih, 2016), sehingga karyawan tidak ingin meninggalkan pekerjaannya karena mereka memerlukannya (Greenberg \& Baron, 2008). Sedangkan komitmen normatif timbul karena adanya rasa keterikatan untuk tetap berada dalam organisasi (Suwandewi \& Sintaasih, 2016), sehingga karyawan tidak ingin meninggalkan pekerjaannya karena didasari keyakinan mengenai apa yang benar serta berhubungan dengan moral, sehingga mereka merasa wajib untuk melakukannya (Greenberg \& Baron, 2008).

Wolowska (2014) mengemukakan bahwa komitmen normatif timbul akibat adanya proses internalisasi terhadap keyakinan bahwa setia pada satu organisasi adalah layak, yang mana hal ini terkait dengan pengalaman sosialisasi individu sejak awal masa kanak-kanaknya baik itu berupa tekanan dari keluarga dan budaya, serta yang berasal dari tempat kerjanya. Hal itu akan menyebabkan timbulnya pengondisian dan proses pemodelan yang mengajarkan pada individu mengenai apa yang berharga dan diharapkan oleh keluarga, budaya ataupun organisasi dari diri mereka. Dominasi budaya juga dapat berpengaruh pada pengembangan komitmen normatif, dimana budaya yang didominasi oleh nilai-nilai kolektif dan lebih menekankan pada keeratan hubungan antara karyawan dan organisasi akan menyebabkan lebih tingginya komitmen normatif daripada budaya yang didominasi oleh nilai-nilai individualistik yang lebih menekankan pada kesempatan kerja karyawan. Meyer dan Allen dalam Wolowska (2014) berpendapat pula bahwa organisasi dapat meningkatkan komitmen normatif karyawannya dengan cara memberikan investasi khusus yang benar-benar dirasakan bermanfaat atau berharga oleh karyawan, seperti meningkatkan kompetensi karyawan dengan cara menyekolahkan atau memberi pelatihan dan ketrampilan pada karyawan. Dengan demikian karyawan merasa bertanggung jawab untuk membalas atau berlaku timbal balik pada organisasinya. Sedangkan Rousseau dalam Wolowska (2014) menjelaskan adanya 'kontrak psikologis' berupa serangkaian harapan tak tertulis yang berlaku sepanjang waktu antara karyawan dan organisasi yang juga dapat menyebabkan berkembangnya komitmen normatif.

Hasil penelitian ini secara simultan membuktikan pula bahwa semua aspek karakteristik demografi menunjukkan pengaruh yang bermakna terhadap organizational citizenship behavior (OCB), sedangkan secara parsial hanya tingkat pendidikan yang menunjukkan pengaruh yang positif dan bermakna terhadap $O C B$, dalam arti jika seorang karyawan memiliki tingkat pendidikan yang tinggi, maka karyawan tersebut akan memiliki OCB yang tinggi pula. Dalam penelitian ini ditemukan OCB tingkat tinggi sebagian besar dimiliki oleh 
karyawan yang berpendidikan S2 (3,7\%). Karolidis (2016) mengemukakan bahwa hubungan antara karyawan yang berpendidikan lebih tinggi dengan organisasinya tidak bersifat normatif ataupun disengaja semata, namun lebih bersifat sosial dimana mereka lebih menekankan pentingnya perilaku menolong dibandingkan karyawan yang kurang berpendidikan. Penelitian Cohen dan Avrahami dalam Karolidis (2016) di sebuah rumah sakit umum menemukan adanya keterkaitan dan efek positif dari tingkat pendidikan pada OCB. Demikian pula dengan penelitian Noble dalam Karolidis (2016) yang dilakukan pada kelompok yang terdiri dari berbagai profesi membuktikan bahwa antara tingkat pendidikan dan OCB terdapat hubungan yang signifikan terutama pada dimensi civic virtue. Ditemukan pula bahwa OCB tingkat sedang cenderung dimiliki oleh hampir semua karyawan dengan berbagai tingkat pendidikan, sedangkan OCB tingkat tinggi cenderung dimiliki oleh karyawan dengan tingkat pendidikan master. Adapun hasil penelitian Mahnaz, Mehdi, Jafar dan Abbolghasem (2013) menunjukkan bahwa tingkat presentasi OCB tertinggi diantara para karyawan dijumpai pada anggota staf dengan gelar MS. Sedangkan penelitian Ng dan Feldman (2009) membuktikan bahwa ada hubungan positif antara tingkat pendidikan pasca sarjana dan kinerja keanggotaan, dimana karyawan yang berpendidikan pasca sarjana master mampu memenuhi harapan pimpinan mereka dengan cara mengerjakan tugas-tugas mereka dalam kelompok agar lebih efektif.

\section{SIMPULAN}

Sebagian besar karyawan dalam penelitian ini berusia $>40$ tahun $(64,7 \%)$, berjenis kelamin laki-laki $(58,9 \%)$, memiliki tingkat pendidikan S1 $(43,2 \%)$, telah menikah $(83,2 \%)$, dan masa kerjanya $\geq 15$ tahun (66,3\%). Mayoritas karyawan memiliki komitmen afektif tingkat sedang $(51,1 \%)$, komitmen kontinuans tingkat sedang $(72,6 \%)$, komitmen normatif tingkat sedang $(71,1 \%)$, dan OCB tingkat sedang $(57,9 \%)$. Sebagian besar karyawan dalam penelitian ini memiliki komitmen organisasi dan organizational citizenship behavior (OCB) tingkat sedang.

Secara simultan, seluruh aspek komitmen organisasi (komitmen afektif, komitmen kontinuans, komitmen normatif) dan seluruh aspek karakteristik demografi (umur, jenis kelamin, tingkat pendidikan, status pernikahan, masa kerja) menunjukkan pengaruh yang bermakna terhadap OCB. Secara parsial, komitmen normatif dan tingkat pendidikan menunjukkan pengaruh yang positif dan bermakna terhadap OCB. Dibandingkan tingkat pendidikan, komitmen normatif menunjukkan pengaruh yang lebih bermakna terhadap OCB.

Hasil penelitian ini dapat digunakan sebagai bahan masukan bagi organisasi agar lebih memahami dan meningkatkan aspek komitmen organisasi dan OCB karyawannya. Dalam penelitian ini ditemukan bahwa komitmen normatif dan tingkat pendidikan karyawan memiliki pengaruh yang positif dan bermakna terhadap $O C B$, sehingga organisasi perlu memperhatikan kedua aspek tersebut untuk meningkatkan OCB karyawannya. Adanya komitmen normatif menyebabkan karyawan setia kepada organisasi karena mereka merasa bahwa setia kepada organisasi adalah sebuah kewajiban, sehingga untuk meningkatkan komitmen normatif karyawan, maka organisasi dapat melakukannya dengan memberikan sesuatu yang bermanfaat bagi mereka, seperti membiayai pelatihan kerja karyawan ataupun menyekolahkan mereka. Adanya bantuan yang bermanfaat ini akan menyebabkan karyawan merasa wajib setia kepada organisasi.

Bagi peneliti lainnya yang tertarik meneliti aspek serupa, diharapkan dapat mengembangkan penelitiannya dengan menggunakan variabel lain yang lebih kompleks seperti tipe kepribadian, tipe kepemimpinan (leadership), budaya organisasi, iklim organisasi, dan keadilan kerja yang juga dapat berpengaruh terhadap OCB karyawan; serta dapat menggunakan populasi dan sampel yang lebih besar daripada penelitian ini.

\section{PUSTAKA ACUAN}

Bolat, OI \& Bolat, T 2008, 'Otel işletmelerinde orgütsel bağlılık ve orgütsel vatandaşlık davranışı ilişkisi', Balıkesir Üniversitesi Sosyal Bilimler Enstitüsü Dergisi, vol 11, no. 19, pp. 75-94. Retrieved from: http://dergipark.gov.tr/download/article-file/235282 
Djati, SP \& Rini, WA 2011, 'Penerapan organizational citizenship behavior dalam manajemen sumber daya manusia pada perguruan tinggi', Jurnal Mitra Ekonomi dan Manajemen Bisnis,vol 2, no. 2, pp. 259-272.

Retrieved from: http://idei.or.id/download/penerapan-organizational-citizenshipbehavior-dalam-manajemen-sumber-daya-manusia-pada-perguruan-tinggi/

Greenberg, J \& Baron, RA 2008, 'Participative decision making and organizational commitment comparing nigerian and american employees, cross cultural management', An International Journal, vol 17, no. 4.

Retrieved from: http://ejournal.uajy.ac.id/2634/6/5EM16565.pdf

Jaros, S 2007, 'Meyer and Allen model of organizational commitment: measurement issues', The Icfai Journal of Organizational Behavior, vol 6, no. 4, pp. 7-25. Retrieved from: https://www.academia.edu/35387821/7_Meyer_and_Allen_Model_of_Organizational _Commitment_Measurement_Issues_Meyer_and_Allen_Model_of_Organizational_Co mmitment_Measurement_Issues

Javanmard, S, Mo'tamedi, A \& Pirmorad, T 2014, 'The survey of the nurses' organizational citizenship behavior according to the generativity moderating-role: a developmental approach', The Journal of Behavioral Sciences, vol 8, no. 4, pp. 355-363.

Retrieved from: http://www.ijmrhs.com/medical-research/the-relationship-betweenorganizational-commitment-components-and-organizational-citizenship-behavior-innursing-staff.pdf

Karolidis, D 2016, 'Organizational citizenship behavior in the greek public sector', A thesis, University of Macedonia. Retrieved from : https://dspace.lib.uom.gr/bitstream/2159/18829/6/KarolidisDimitriosMsc2016.pdf

Kumar, MM \& Shah, SA 2015, 'Psychometric properties of podsakoff's organizational citizenship behaviour scale in the asian context', The International Journal of Indian Psychology, vol 3, no. 9, pp. 51-60. Retrieved from: https://www.researchgate.net/profile/Mohd_Kumar2/publication/317664724_Psycho metric_Properties_of_Podsakoff\%27s_Organizational_Citizenship_Behaviour_Scale_in _the_Asian_Context/links/594815a2458515db1fd6ef22/Psychometric-Properties-ofPodsakoffs-Organizational-Citizenship-Behaviour-Scale-in-the-AsianContext.pdf?origin=publication_detail

Kurniawan, A 2015, 'Pengaruh komitmen organisasi terhadap organizational citizenship behavior (ocb) PT X Bandung', Jurnal Manajemen, vol 15, no. 1, pp. 95-118. Retrieved from: http://majour.maranatha.edu/index.php/jurnal-manajemen/article/view/1452

Mahnaz, MA, Mehdi, M, Jafar, KM \& Abbolghasem, P 2013, 'The effect of demographic characteristics on organizational citizenship behavior in the selected teaching hospitals in tehran', African Journal of Business Management, vol 7, no. 34, pp. 3324-3331. Retrieved from : http://www.academicjournals.org/article/article1380701466_Mahnaz\%20et\%20al.pdf

$\mathrm{Ng}$, TW \& Feldman, DC 2009, 'How broadly does education contribute to job performance?', Personnel Psychology, vol 62, no. 1, pp. 89-134. Retrieved from: https://dspace.lib.uom.gr/bitstream/2159/18829/6/KarolidisDimitriosMsc2016.pdf

Olorunniwo, F, Hsu, MK \& Udo, GF 2006, 'Service quality, customer satisfaction, and behaviour intentions in the service factory', Journal of Service Marketing, vol 20, no. 1, pp. 59-72. Retrieved from:

http://fportfolio.petra.ac.id/user_files/91-023/OCB-SERVICE\%20JOURNALS.Pantja.Djati.doc.

Rahmawati, T \& Prasetya, A 2017, 'Analisis faktor-faktor yang mempengaruhi organizational citizenship behavior (ocb) pada karyawan tetap dan karyawan kontrak', Jurnal Administrasi Bisnis (JAB), vol 48, no. 1, pp. 97-106. Retrieved from: https://media.neliti.com/media/publications/88095-ID-analisisfaktor-faktor-yangmempengaruhi.pdf

Ramli 2008, 'Back to the future', Campus, vol 2, no. 1. Retrieved from: 
http://idei.or.id/download/penerapan-organizational-citizenship-behavior-dalammanajemen-sumber-daya-manusia-pada-perguruan-tinggi/

Salajagheh, S, Safdaryan, A \& Kheyri, B 2014, 'The relationship between the organizational commitment components and the pestle's model factors from the perspective of the individuals eligible for physicians and paramedics military service obligations in isfahan medical sciences university (a strategic approach)', The Journal of Health System Studies, vol 1, no. 10, pp. 30-38. Retrieved from: http://www.ijmrhs.com/medicalresearch/the-relationship-between-organizational-commitment-components-andorganizational-citizenship-behavior-in-nursing-staff.pdf

Sena, TF 2011, 'Variabel antiseden organizational citizenship behavior (ocb)', Jurnal Dinamika Manajemen, vol 2, no. 1, pp. 70-77. Retrieved from : https://ojs.unud.ac.id/index.php/Manajemen/article/view/21930/14751

Supriyanto, S \& Djohan, AJ 2011, Metodologi riset bisnis dan kesehatan, PT Grafika Wangi Kalimantan, Banjarbaru.

Suwandewi, NN \& Sintaasih, DK 2016, 'Keadilan organisasional dan komitmen organisasional: efeknya pada organizational citizenship behavior', E-Jurnal Manajemen Unud, vol 5, no. 7, pp. 4453-4485. Retrieved from: https://ojs.unud.ac.id/index.php/Manajemen/article/view/21930/14751

Syauta, JH, Eka, AT, Margono, S \& Solimun 2012, 'The influence of organizational culture, organizational commitment to job satisfaction and employee performance', International Journal of Business and Management Invention, vol 1, no. 1, pp. 69-76. Retrieved from: http://journal.unhas.ac.id/index.php/mkmi/article/view/1982/pdf

Wolowska, A 2014, 'Determinants of organizational commitment', Human Resources Management \& Ergonomics, vol 8, no. 1, pp. 129-146. Retrieved from: https://frcatel.fri.uniza.sk/hrme/files/2014/2014_1_10.pdf

Wulandari, P 2015, 'Pengaruh kepuasan kerja dan komitmen organisasi terhadap organizational citizenship behavior perawat rumah sakit islam yogyakarta', (Skripsi, tidak diterbitkan), Universitas Negeri Yogyakarta. Retrieved from: http://eprints.uny.ac.id/14889/1/SKRIPSI.pdf 